ARTICLE

https://doi.org/10.1038/s41467-019-11970-8

\title{
Origin of synergistic effects in bicomponent cobalt oxide-platinum catalysts for selective hydrogenation reaction
}

Jiankang Zhang ${ }^{1,2}$, Zhe Gao ${ }^{1}$, Sen Wang ${ }^{1}$, Guofu Wang ${ }^{1}$, Xiaofeng Gao1,2, Baiyan Zhang ${ }^{1,2}$, Shuangfeng Xing 1,2, Shichao Zhao ${ }^{1} \&$ Yong Qin (1) ${ }^{1,2}$

The synergistic nature of bicomponent catalysts remains a challenging issue, due to the difficulty in constructing well-defined catalytic systems. Here we study the origin of synergistic effects in $\mathrm{CoO}_{x}-\mathrm{Pt}$ catalysts for selective hydrogenation by designing a series of closely contacted $\mathrm{CoO}_{x} \mathrm{Pt} / \mathrm{TiO}_{2}$ and spatially separated $\mathrm{CoO}_{x} / \mathrm{TiO}_{2} / \mathrm{Pt}$ catalysts by atomic layer deposition (ALD). For $\mathrm{CoO}_{x} / \mathrm{TiO}_{2} / \mathrm{Pt}, \mathrm{CoO}_{x}$ and platinum are separated by the walls of titania nanotubes, and the $\mathrm{CoO}_{x}-\mathrm{Pt}$ intimacy can be precisely tuned. Like $\mathrm{CoO}_{x} \mathrm{Pt} / \mathrm{TiO}_{2}$, the $\mathrm{CoO}_{x} / \mathrm{TiO}_{2} / \mathrm{Pt}$ shows higher selectivity to cinnamyl alcohol than monometallic $\mathrm{TiO}_{2} / \mathrm{Pt}$, indicating that the $\mathrm{CoO}_{x}-\mathrm{Pt}$ nanoscale intimacy almost has no influence on the selectivity. The enhanced selectivity is ascribed to the increased oxygen vacancy resulting from the promoted hydrogen spillover. Moreover, platinum-oxygen vacancy interfacial sites are identified as the active sites by selectively covering $\mathrm{CoO}_{x}$ or platinum by ALD. Our study provides a guide for the understanding of synergistic nature in bicomponent and bifunctional catalysts.

\footnotetext{
${ }^{1}$ State Key Laboratory of Coal Conversion, Institute of Coal Chemistry, Chinese Academy of Sciences, 27 Taoyuan South Road, 030001 Taiyuan, P.R. China. ${ }^{2}$ Center of Materials Science and Optoelectronics Engineering, University of Chinese Academy of Sciences, 100049 Beijing, P.R. China. Correspondence and requests for materials should be addressed to Z.G. (email: gaozhe@sxicc.ac.cn) or to Y.Q. (email: qinyong@sxicc.ac.cn)
} 
B icomponent catalysts have received considerably increasing interests in the recent decades due to the enhanced catalytic properties compared with their single-component counterparts, arising from direct contact between the two components, which can be called as synergistic effects ${ }^{1,2}$. However, due to the limitations in controlling the catalyst microstructures and precisely tuning bicomponent intimacy by the traditional methods, it is still a challenging issue to understand the origin of synergistic effects (i.e., short- or long-range interactions) and identify the active sites.

The general belief is that the bicomponents should be as close as possible (i.e., short-range interactions of bicomponents) to promote electron interaction and/or construct interfaces to achieve effective catalysis. In this case, the interaction of a metal oxide promoter with a metal particle is puzzling due to the presence of multiple potential catalytic active sites under the reaction conditions. In contrast, some recent reports revealed the effects of intimacy on the catalyst performance when the bicomponents are separated and tuned at nanoscale and even millimeter-scale distance (i.e., long-range interactions of bicomponents) ${ }^{3-10}$. For example, Coville and coworkers investigated the effect of Ru and Co intimacy on the activity and selectivity of Co catalysts using conventional incipient wetness impregnation in the typical Fischer-Tropsch reaction ${ }^{5}$. Bokhoven and coworkers prepared a series of model catalyst samples with precisely controlled $\mathrm{Pt}-\mathrm{FeO}_{x}$ intimacy at nanoscale distances using the more precise nanolithography technique, and investigated the hydrogen spillover effects on $\mathrm{TiO}_{2}$ and $\mathrm{Al}_{2} \mathrm{O}_{3}$ supports ${ }^{7}$. But no reaction (not possible for such structure) is conducted to verify the proposed hydrogen spillover mechanism under the real reaction conditions. Therefore, well-defined bicomponent catalytic systems are highly desirable to unravel the origin of synergistic effects under the real reaction conditions.

Atomic layer deposition (ALD) is a powerful thin-film technique for synthesis of conformal thin films and highly dispersed nanoparticles ${ }^{1-16}$. Many advanced nanocatalysts have been designed and synthesized by ALD in the past decade ${ }^{17-26}$. Herein, we investigate the effects of $\mathrm{CoO}_{x}-\mathrm{Pt}$ intimacy on the selective hydrogenation of cinnamaldehyde (CALD) and the hydrogen spillover effects based on $\mathrm{CoO}_{x} \mathrm{Pt} / \mathrm{TiO}_{2}$ and well-designed spatially separated structures of $\mathrm{CoO}_{x} / \mathrm{TiO}_{2} / \mathrm{Pt}$ catalysts by a highly controllable and reliable ALD approach. Compared with the $\mathrm{CoO}_{x} \mathrm{Pt} / \mathrm{TiO}_{2}$, the $\mathrm{CoO}_{x} / \mathrm{TiO}_{2} / \mathrm{Pt}$ catalysts exhibit similar catalytic activity and hydrogenation selectivity for the CALD hydrogenation, though the $\mathrm{CoO}_{x}-\mathrm{Pt}$ intimacy of the two catalysts is dramatically different. This long-range promoter effect is not broken even when we selectively deposit additional coating layers on the $\mathrm{CoO}_{x}$ surfaces by ALD. The enhanced selectivity is ascribed to the promoted hydrogen spillover and thus increased oxygen vacancies $\left(\mathrm{O}_{\mathrm{v}}\right)$. The well-designed structures can be synthesized and used to study the synergetic natures of other bicomponent and bifunctional catalysts with enhanced performance for other reactions.

\section{Results}

Synthesis and characterization of the catalysts. The closely contacted $\mathrm{CoO}_{x} \mathrm{Pt} / \mathrm{TiO}_{2}$ and spatially separated $\mathrm{CoO}_{x} / \mathrm{TiO}_{2} / \mathrm{Pt}$ catalysts were synthesized by a template-assisted ALD strategy (Fig. 1 and Supplementary Scheme 1$)^{26}$. For the synthesis of $\mathrm{CoO}_{x} \mathrm{Pt} / \mathrm{TiO}_{2}$, an amorphous $\mathrm{TiO}_{2}$ film was first deposited on carbon nanocoils (CNCs) used as templates by ALD, obtaining $\mathrm{TiO}_{2} / \mathrm{CNCs}$, and then Pt nanoparticles were deposited on the $\mathrm{TiO}_{2} / \mathrm{CNCs}$ by Pt ALD, obtaining Pt/TiO $/$ CNCs. Subsequently, the CNCs were removed by calcination under an air atmosphere, producing $\mathrm{Pt} / \mathrm{TiO}_{2}$ catalysts with anatase nanotubes. Lastly, $\mathrm{CoO}_{x}$ nanoparticles were deposited on the outer surface of the $\mathrm{Pt} / \mathrm{TiO}_{2}$ through $\mathrm{CoO}_{x} \mathrm{ALD}$, producing $\mathrm{CoO}_{x} \mathrm{Pt} / \mathrm{TiO}_{2}$ catalysts with the closest $\mathrm{CoO}_{x}-\mathrm{Pt}$ intimacy (Supplementary Scheme 1a). The $\mathrm{CoO}_{x} / \mathrm{TiO}_{2} / \mathrm{Pt}$ catalysts were prepared by exchanging the deposition sequence of $\mathrm{TiO}_{2}$ and Pt (Supplementary Scheme 1b). The $\mathrm{CoO}_{x}-\mathrm{Pt}$ intimacy can be precisely controlled by adjusting the thickness of $\mathrm{TiO}_{2}$ layer. In addition, the $\mathrm{CoO}_{x} / \mathrm{TiO}_{2} / \mathrm{Pt} / \mathrm{TiO}$ and $\mathrm{Al}_{2} \mathrm{O}_{3} / \mathrm{CoO}_{x} / \mathrm{TiO}_{2} / \mathrm{Pt}$ catalysts (Fig. 1) were also prepared by selectively covering $\mathrm{Pt}$ with $\mathrm{TiO}_{2}$ and $\mathrm{CoO}_{x}$ nanoparticles with $\mathrm{Al}_{2} \mathrm{O}_{3}$, respectively, to identify the real active sites in the bicomponent catalysts.

Figure 2 shows the transmission electron microscopy (TEM) and high-resolution TEM (HRTEM) images of the $\mathrm{CoO}_{x} \mathrm{Pt} / \mathrm{TiO}_{2}$ and $\mathrm{CoO}_{x} / \mathrm{TiO}_{2} / \mathrm{Pt}$ catalysts, prepared with 150, 20 and 300 cycles for $\mathrm{CoO}_{\mathrm{x}}, \mathrm{Pt}$ and $\mathrm{TiO}_{2}$ deposition, respectively. The Pt and $\mathrm{CoO}_{x}$ nanoparticles, with average sizes of $2.9 \mathrm{~nm}$ and $4.3 \mathrm{~nm}$, respectively (Supplementary Figs. 1 and 2), are highly dispersed on the outer surface of the anatase $\mathrm{TiO}_{2}$ nanotubes with a wall thickness of $\sim 13.7 \mathrm{~nm}$, in which $\mathrm{CoO}_{x}$ is deposited on/next to $\mathrm{Pt}$ forming $\mathrm{CoO}_{x}-\mathrm{Pt}$ interfaces (Fig. 2a, b). The measured lattice distances of the nanoparticles are $\sim 0.223 \mathrm{~nm}$ and $\sim 0.246 \mathrm{~nm}$ (Fig. 2b), which correspond to the $\mathrm{Pt}(111)$ and $\mathrm{CoO}$ (111) planes,

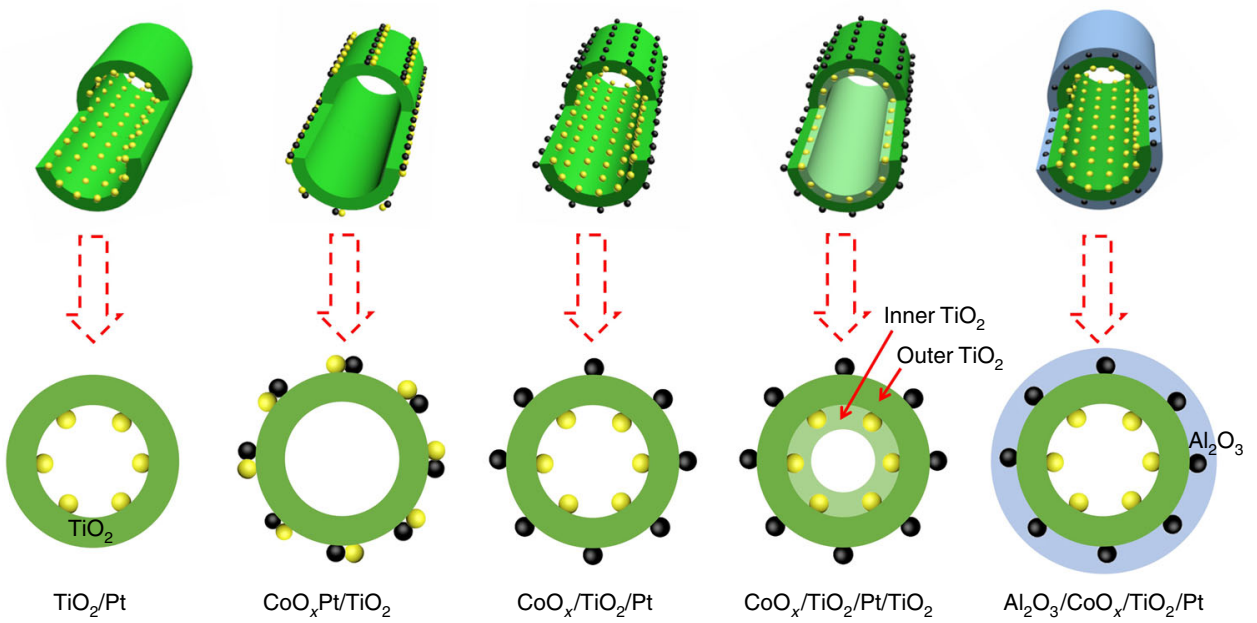

Fig. 1 Schematic illustration of the catalysts. Semi-sectional and cross-sectional views of the different catalysts prepared by ALD. The yellow and black balls represent $\mathrm{Pt}$ and $\mathrm{CoO}_{x}$, respectively 
respectively ${ }^{27,28}$. The larger lattice distance of $0.350 \mathrm{~nm}$ matches well with (101) planes of anatase $\mathrm{TiO}_{2}^{26}$. For the $\mathrm{CoO}_{x} / \mathrm{TiO}_{2} / \mathrm{Pt}$ catalyst (Fig. 2c, d), Pt nanoparticles (indicated by yellow circles) with an average particle size of $3.1 \mathrm{~nm}$ (Supplementary Fig. 3) are uniformly deposited on the inner surface of the $\mathrm{TiO}_{2}$ nanotubes, while $\mathrm{CoO}_{x}$ nanoparticles are uniformly deposited on the outer surface of the $\mathrm{TiO}_{2}$ nanotubes (Supplementary Fig. 4). In $\mathrm{CoO}_{x} \mathrm{Pt} / \mathrm{TiO}_{2}$ catalysts, the $\mathrm{Pt}$ nanoparticles are closely contacted with $\mathrm{CoO}_{x}$ nanoparticles, while in $\mathrm{CoO}_{x} / \mathrm{TiO}_{2} / \mathrm{Pt}$ catalysts, the
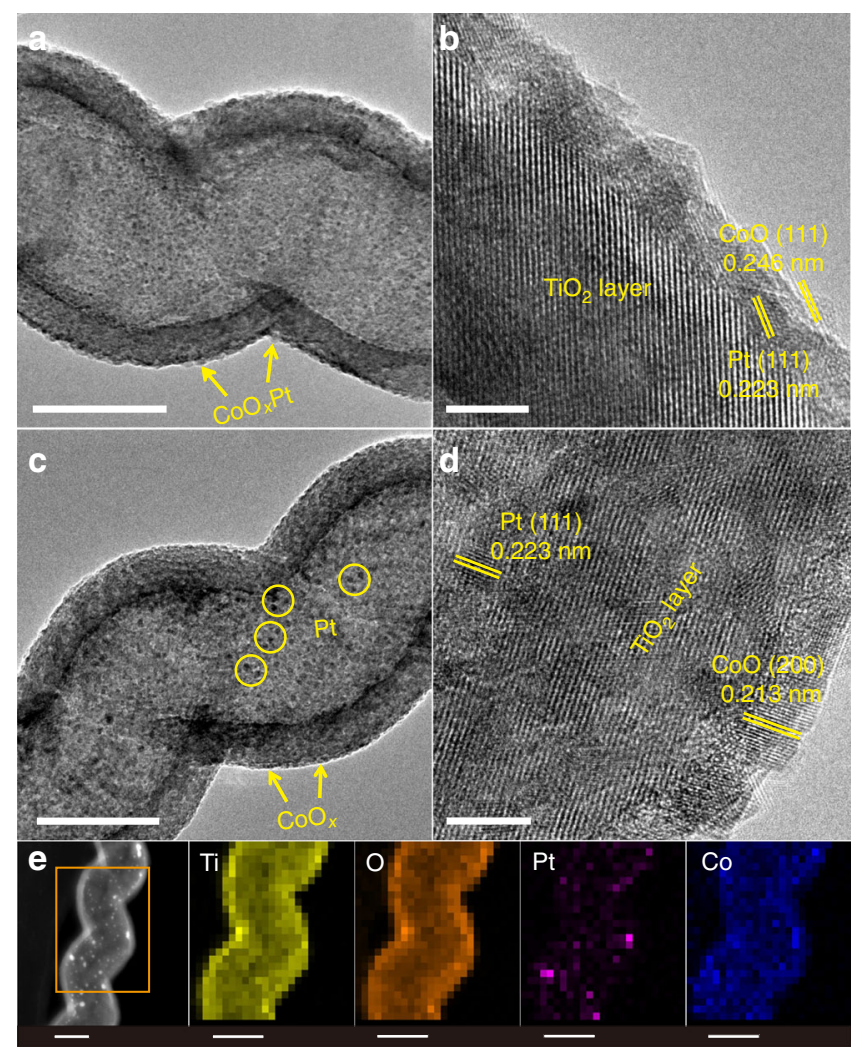

Fig. 2 Structural characterizations of the two catalysts. TEM and HRTEM images of the $\mathrm{CoO}_{x} \mathrm{Pt} / \mathrm{TiO}_{2}(\mathbf{a}, \mathbf{b})$ and $\mathrm{CoO}_{x} / \mathrm{TiO}_{2} / \mathrm{Pt}(\mathbf{c}, \mathbf{d})$ catalysts. e STEM image of the $\mathrm{CoO}_{x} / \mathrm{TiO}_{2} / \mathrm{Pt}$ catalysts and the corresponding EDS mapping profiles in rectangular area. Scale bars: a, c and e $50 \mathrm{~nm}$; b and d $5 \mathrm{~nm}$ average $\mathrm{CoO}_{x}-\mathrm{Pt}$ distance is corresponded to the $\mathrm{TiO}_{2}$ thickness. Thus the average $\mathrm{CoO}_{x}-\mathrm{Pt}$ distance in $\mathrm{CoO}_{x} \mathrm{Pt} / \mathrm{TiO}_{2}$ is much smaller than that of $\mathrm{CoO}_{x} / \mathrm{TiO}_{2} / \mathrm{Pt}$. The sample was further characterized by using high-angle annular dark-field scanning TEM (HAADF-STEM), and energy-dispersive X-ray spectroscopy (EDS) mapping (Fig. 2e and Supplementary Figs. 5 and 6), further confirming that the $\mathrm{Pt}$ and $\mathrm{CoO}_{x}$ nanoparticles are separately decorated on the inner and outer surfaces of the $\mathrm{TiO}_{2}$ nanotubes, respectively.

Catalytic performance. The selective hydrogenation of $\mathrm{C}=\mathrm{O}$ in $\alpha, \beta$-unsaturated aldehydes (e.g., CALD) to value-added unsaturated alcohols has been of increasing interest for the production of fine chemicals and pharmaceutical precursors ${ }^{29-38}$. However, it remains challenging to achieve high-yield unsaturated alcohols since the hydrogenation of $\mathrm{C}=\mathrm{C}$ is thermodynamically more favorable than that of $\mathrm{C}=\mathrm{O}$. To address the issue, various catalysts have been designed and synthesized, and Pt-based catalysts were found to be more desirable in the selective reduction of $\mathrm{C}=\mathrm{O}$ than other metals ${ }^{29-38}$. Bitter and coworkers found that $\mathrm{Pt}$ particle size and oxygen groups on carbon nanofiber supports have a vital influence on the selectivity to cinnamyl alcohol $(\mathrm{CALC})^{29}$. Chen and coworkers reported that $\mathrm{Co}-\mathrm{Pt} / \mathrm{SiO}_{2}$ bimetallic catalysts exhibit better catalytic activity and selectivity than $\mathrm{Pt} / \mathrm{SiO}_{2}$ and $\mathrm{Cu}-\mathrm{Pt} / \mathrm{SiO}_{2}$ catalysts due to the electronic property modification of $\mathrm{Pt}^{30,31}$. Similar results were also reported by Tsang et al., i.e., the selective $\mathrm{C}=\mathrm{O}$ hydrogenation can be achieved with high activity using Co-decorated Pt nanocrystals as nanocatalysts ${ }^{38}$.

To unravel the synergetic mechanism, the selective hydrogenation of CALD is selected as an example to evaluate the catalytic properties of the as-prepared catalysts, and the results are summarized in Table 1 . Note that the Pt nanoparticles are located at different positions for the $\mathrm{Pt} / \mathrm{TiO}_{2}$ and $\mathrm{TiO}_{2} / \mathrm{Pt}$ catalysts. For the monometallic $\mathrm{TiO}_{2} / \mathrm{Pt}$ catalyst with $\mathrm{Pt}$ loading of $3.7 \mathrm{wt} . \%$ (Supplementary Table 1), the main product is hydrocinnamaldehyde (HALD) obtained from hydrogenation of the $\mathrm{C}=\mathrm{C}$ and the selectivity to HALD amounts to $62.5 \%$, while the selectivity to the desired product CALC, obtained from hydrogenation of the $\mathrm{C}=\mathrm{O}$, is only $16.2 \%$ (Entry 1 ). For the $\mathrm{CoO}_{x} / \mathrm{TiO}_{2}$ reference catalyst, only trace conversion $(0.9 \%)$ is detected under the same reaction conditions (Entry 2). For the $\mathrm{CoO}_{x} \mathrm{Pt} / \mathrm{TiO}_{2}$ catalysts with closely contacted $\mathrm{Pt}$ and $\mathrm{CoO}_{x}$, the selectivity to CALC is remarkably improved after addition of $\mathrm{CoO}_{x}$ (Entry 3). Moreover,

\section{Table 1 Selective hydrogenation results of CALD over the different catalysts ${ }^{a}$}

\begin{tabular}{|c|c|c|c|c|c|}
\hline \multirow[t]{2}{*}{ Entry } & \multirow[t]{2}{*}{ Catalysts } & \multirow[t]{2}{*}{ Conversion (\%) (CALD) } & \multicolumn{3}{|c|}{ Selectivity (\%) } \\
\hline & & & (CALC) & (HALD) & (HALC) \\
\hline 1 & $\mathrm{TiO}_{2} / \mathrm{Pt}$ & 93.1 & 16.2 & 62.5 & 21.7 \\
\hline 2 & $\mathrm{CoO}_{x} / \mathrm{TiO}_{2}$ & 0.9 & - & - & - \\
\hline 3 & $\mathrm{CoO}_{x} \mathrm{Pt} / \mathrm{TiO}_{2}$ & 92.4 & 82.1 & 14.5 & 3.3 \\
\hline 4 & $\mathrm{CoO}_{x} / \mathrm{TiO}_{2} / \mathrm{Pt}$ & 91.3 & 81.5 & 13.9 & 4.3 \\
\hline 5 & $\mathrm{CoO}_{x} / \mathrm{TiO}_{2}(900) / \mathrm{Pt}^{\mathrm{b}}$ & 89.8 & 80.3 & 14.3 & 4.7 \\
\hline 6 & $\mathrm{CoO}_{x} / \mathrm{TiO}_{2} / \mathrm{Pt} / \mathrm{TiO}_{2}$ & 8.8 & 52.1 & 47.4 & - \\
\hline 7 & $\mathrm{Al}_{2} \mathrm{O}_{3} / \mathrm{CoO}_{x} / \mathrm{TiO}_{2} / \mathrm{Pt}^{\mathrm{C}}$ & 90.2 & 77.8 & 15.9 & 5.8 \\
\hline 8 & $\mathrm{Al}_{2} \mathrm{O}_{3} / \mathrm{Pt}^{\mathrm{d}}$ & 31.8 & - & 100 & - \\
\hline 9 & $\mathrm{CoO}_{x} / \mathrm{Al}_{2} \mathrm{O}_{3} / \mathrm{Pt}$ & 18.5 & 39.1 & 60.7 & - \\
\hline 10 & $\mathrm{CoO}_{x} \mathrm{Pt} / \mathrm{Al}_{2} \mathrm{O}_{3}$ & 27.4 & 69.4 & 30.2 & - \\
\hline 11 & $\mathrm{CoO}_{x} / \mathrm{Al}_{2} \mathrm{O}_{3}$ & 0.2 & - & - & - \\
\hline
\end{tabular}



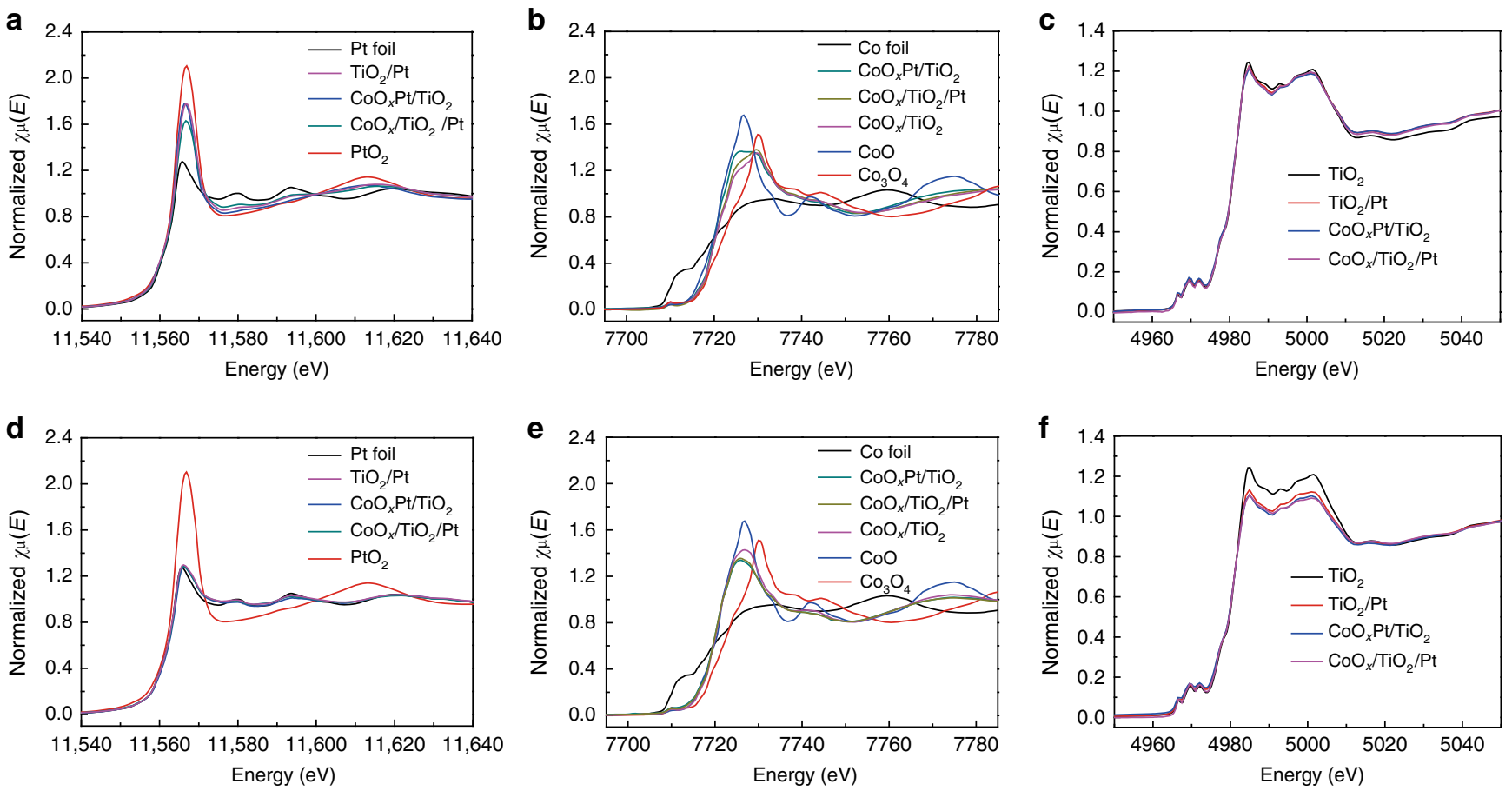

Fig. 3 XANES spectra of the catalysts. a Ex situ and $\mathbf{d}$ in situ Pt $\mathrm{L}_{3}$-edge XANES spectra of $\mathrm{TiO}_{2} / \mathrm{Pt}_{1} \mathrm{CoO}_{x} / \mathrm{TiO}_{2} / \mathrm{Pt}, \mathrm{CoO}_{x} \mathrm{Pt} / \mathrm{TiO}_{2}$, and reference Pt foil and $\mathrm{PtO}_{2} ; \mathbf{b}$ Ex situ and e in situ Co K-edge XANES spectra of $\mathrm{TiO}_{2} / \mathrm{Pt}, \mathrm{CoO}_{x} / \mathrm{TiO}_{2} / \mathrm{Pt}, \mathrm{CoO}_{x} \mathrm{Pt} / \mathrm{TiO}_{2}$, and reference $\mathrm{Co}$ foil, $\mathrm{CoO}$ and $\mathrm{CO}_{3} \mathrm{O}_{4} ; \mathbf{c}$ Ex situ and f in situ Ti K-edge XANES spectra of $\mathrm{TiO}_{2} / \mathrm{Pt}, \mathrm{CoO}_{x} \mathrm{Pt} / \mathrm{TiO}_{2}, \mathrm{CoO}_{x} / \mathrm{TiO}_{2} / \mathrm{Pt}$ and reference $\mathrm{TiO}_{2}$

the product of excessive hydrogenation to hydrocinnamyl alcohol (HALC) is also obviously suppressed. Similar phenomenon is also found for the $\mathrm{CoO}_{x}$-supported Pt-based catalysts, and the Pt40/ $\mathrm{CoO}_{x}$ catalysts exhibit the best catalytic performance with $90.2 \%$ conversion and $80.3 \%$ selectivity to CALC (Supplementary Fig. 7). The improved selectivity to CALC is usually ascribed to the promoter effects, originating from electronic or structural modifications ${ }^{35-41}$. Unexpectedly, similar hydrogenation results are also achieved over the $\mathrm{CoO}_{x} / \mathrm{TiO}_{2} / \mathrm{Pt}(13.7 \mathrm{~nm}, 300$-cycle $\mathrm{TiO}_{2}$ ) catalysts with nanoscale $\mathrm{CoO}_{x}-\mathrm{Pt}$ intimacy (Entry 4 and Supplementary Fig. 8). Moreover, only slight decrease in hydrogenation activity and selectivity is observed over the $\mathrm{CoO}_{x} / \mathrm{TiO}_{2}(900) / \mathrm{Pt}$ catalysts (Entry 5) when the $\mathrm{TiO}_{2}$ layer becomes much thicker $\left(40.5 \mathrm{~nm}, 900\right.$-cycle $\mathrm{TiO}_{2}$, Supplementary Figs. 9 and 10).

Furthermore, control experiments were also carried out by selectively exposing Pt or $\mathrm{CoO}_{x}$ to confirm the roles played by $\mathrm{CoO}_{x}$ and Pt during the reaction. The hydrogenation conversion and selectivity to the desired CALC product decrease remarkably when $\mathrm{Pt}$ is selectively covered by two-layered $\mathrm{TiO}_{2}\left(\mathrm{CoO}_{x} / \mathrm{TiO}_{2} /\right.$ $\mathrm{Pt} / \mathrm{TiO}_{2}$, Entry 6). When $\mathrm{CoO}_{x}$ is selectively covered by an outer dense $\mathrm{Al}_{2} \mathrm{O}_{3}$ layer of $\sim 11.5 \mathrm{~nm}\left(\mathrm{Al}_{2} \mathrm{O}_{3} / \mathrm{CoO}_{x} / \mathrm{TiO}_{2} / \mathrm{Pt}\right)$, no visible change is observed in the catalytic performance (Entry 7). These results indicate that $\mathrm{Pt}-\mathrm{TiO}_{2}$ interface regions should be the main active sites for the CALD hydrogenation reaction, instead of $\mathrm{CoO}_{x}$. It should be noted that the selectivity of CALC hydrogenation is guaranteed to improve with $\mathrm{CoO}_{x}$ addition due to the long-range promoter effect and that this effect is not broken even when the surface of $\mathrm{CoO}_{x}$ promoter is entirely covered by a dense $\mathrm{Al}_{2} \mathrm{O}_{3}$ layer $\left(\mathrm{Al}_{2} \mathrm{O}_{3} / \mathrm{CoO}_{\mathrm{x}} / \mathrm{TiO}_{2} / \mathrm{Pt}\right.$, Entry 7). This effect is altered when the $\mathrm{TiO}_{2}$ layer is changed to $\mathrm{Al}_{2} \mathrm{O}_{3}$ $(\sim 11.5 \mathrm{~nm})$, i.e., the catalytic performance is considerably influenced by the $\mathrm{CoO}_{x}-\mathrm{Pt}$ intimacy (Entries 8-11). Closely contacted $\mathrm{CoO}_{x} \mathrm{Pt} / \mathrm{Al}_{2} \mathrm{O}_{3}$ catalysts exhibit higher activity and selectivity to the desired product than those of the separated $\mathrm{CoO}_{x} / \mathrm{Al}_{2} \mathrm{O}_{3} / \mathrm{Pt}$ catalysts with nanoscale intimacy. This should be related to the poor capability of spillover hydrogen transfer on the nonreducible $\mathrm{Al}_{2} \mathrm{O}_{3}{ }^{7}$. In addition, the reusability of $\mathrm{CoO}_{x} / \mathrm{TiO}_{2} /$ $\mathrm{Pt}$ for selective hydrogenation of CALD was also tested (Supplementary Fig. 11). There is no obvious decrease in the conversion after five catalytic cycles, indicating a good stability of the catalysts.

$\mathrm{X}$-ray absorption fine structure measurements. The electronic states of the $\mathrm{TiO}_{2} / \mathrm{Pt}, \mathrm{CoO}_{x} / \mathrm{TiO}_{2} / \mathrm{Pt}$ and $\mathrm{CoO}_{x} \mathrm{Pt} / \mathrm{TiO}_{2}$ catalysts before and during the hydrogenation reaction processes were investigated by ex situ and in situ X-ray absorption fine structure measurements (Fig. 3). Figure 3a shows the normalized $\mathrm{Pt} \mathrm{L}_{3}$ edge ex situ X-ray absorption near-edge structure (XANES) spectra of the as-prepared catalysts, and the reference spectra of $\mathrm{Pt}$ foil and $\mathrm{PtO}_{2}$. The white line intensity of the as-prepared catalysts falls in the range between the $\mathrm{Pt}$ foil and $\mathrm{PtO}_{2}$, suggesting that the as-prepared Pt nanoparticles consist of a certain amount of $\mathrm{PtO}_{x}$ in addition to metallic $\mathrm{Pt}^{0}$. Expanded view of the white lines (Supplementary Fig. 12) indicates the different electronic states of $\mathrm{Pt}$ for $\mathrm{TiO}_{2} / \mathrm{Pt}, \mathrm{CoO}_{x} / \mathrm{TiO}_{2} / \mathrm{Pt}$ and $\mathrm{CoO}_{x} \mathrm{Pt} / \mathrm{TiO}_{2}$ catalysts. Figure $3 \mathrm{~b}$ presents the normalized Co K-edge XANES spectra of the as-prepared catalysts before the reaction, and the reference spectra of $\mathrm{Co}$ foil, $\mathrm{CoO}$ and $\mathrm{Co}_{3} \mathrm{O}_{4}$. Obviously, the $\mathrm{CoO}_{x} / \mathrm{TiO}_{2} / \mathrm{Pt}$ catalysts also exhibit different white line shapes in comparison with the $\mathrm{CoO}_{x} \mathrm{Pt} / \mathrm{TiO}_{2}$ catalysts, indicating the different electronic states of the $\mathrm{CoO}_{x}$ species between the two catalysts. These results demonstrate that before the reaction, the electronic interaction between $\mathrm{CoO}_{x}$ promoter and $\mathrm{Pt}$ should exist (Supplementary Fig. 13). During the reaction process, the $\mathrm{PtO}_{x}$ species of $\mathrm{TiO}_{2} / \mathrm{Pt}, \mathrm{CoO}_{x} / \mathrm{TiO}_{2} / \mathrm{Pt}$ and $\mathrm{CoO}_{x} \mathrm{Pt} / \mathrm{TiO}_{2}$ are fully reduced to metallic $\mathrm{Pt}^{0}$ due to the presence of $\mathrm{H}_{2}$ (Fig. 3d). The Fourier transform spectra of the $\mathrm{Pt}_{3}$-edge extended X-ray absorption fine structure (EXAFS) oscillations for these three catalysts also confirm the full reduction of $\mathrm{PtO}_{x}$ during the reaction process (Supplementary Fig. 14a, b). For the $\mathrm{CoO}_{x} / \mathrm{TiO}_{2}$ reference catalysts, the white line shifts to a low energy during the 
a

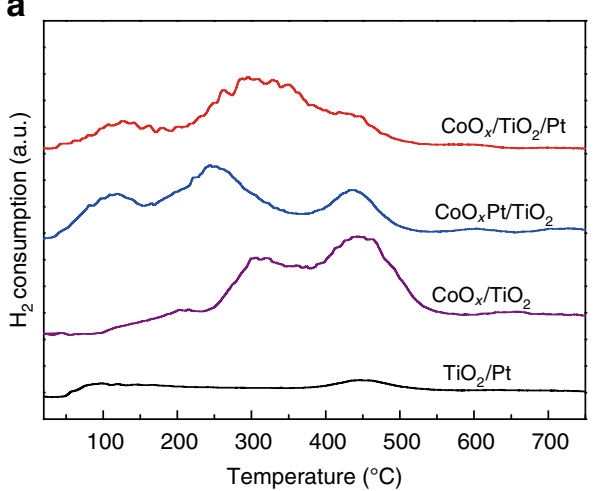

b

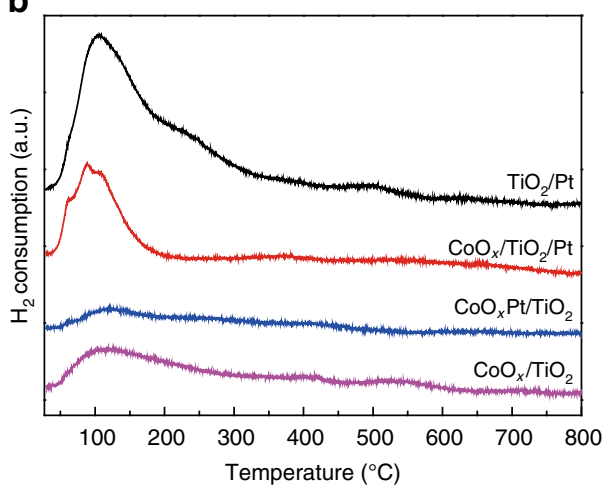

Fig. 4 Chemisorption characterizations. a $\mathrm{H}_{2}$-TPR and $\mathbf{b} \mathrm{H}_{2}$-TPD profiles of the catalysts

reaction process (Fig. $3 \mathrm{~b}$ and e), indicating that the cobalt oxide species at high valence could be reduced to relatively low valence states (e.g., from $\mathrm{Co}_{3} \mathrm{O}_{4}$ to $\mathrm{CoO}$ ) under a $\mathrm{H}_{2}$ atmosphere without Pt assistance (Supplementary Fig. 14c, d). Lower energy shifts of the white lines can be observed for the $\mathrm{CoO}_{x} \mathrm{Pt} / \mathrm{TiO}_{2}$ and $\mathrm{CoO}_{x} / \mathrm{TiO}_{2} / \mathrm{Pt}$ catalysts during the reaction process, demonstrating that more cobalt oxide species with lower valence states are formed in the two catalysts compared with the $\mathrm{CoO}_{x} / \mathrm{TiO}_{2}$ catalysts, which can be ascribed to the presence of Pt contributing to the reduction of $\mathrm{CoO}_{x}$ due to the hydrogen spillover effect. In addition, the $\mathrm{CoO}_{x} \mathrm{Pt} / \mathrm{TiO}_{2}$ and $\mathrm{CoO}_{x} / \mathrm{TiO}_{2} / \mathrm{Pt}$ catalysts exhibit almost the same white line shapes during the reaction process (Fig. 3e), i.e., the valence states of the formed cobalt oxide species of the two catalysts are nearly identical; this is due to the strong reduction ability of the spillover hydrogen $(\mathrm{H} \cdot)$, generated on $\mathrm{Pt}$, toward $\mathrm{CoO}_{x}$, which is nearly independent of the $\mathrm{CoO}_{x}-\mathrm{Pt}$ intimacy on reducible $\mathrm{TiO}_{2}$ supports in the nanoscale range ${ }^{7}$.

Figure $3 \mathrm{c}$ and $\mathrm{f}$ shows the normalized Ti K-edge ex situ and in situ XANES spectra of $\mathrm{TiO}_{2} / \mathrm{Pt}, \mathrm{CoO}_{x} / \mathrm{TiO}_{2} / \mathrm{Pt}, \mathrm{CoO}_{x} \mathrm{Pt} / \mathrm{TiO}_{2}$ and the reference spectra of $\mathrm{TiO}_{2}$. Before the reaction, the Ti Kedge white line curves of all the three catalysts coincide, indicating the same electronic states of their $\mathrm{TiO}_{2}$ supports. During the hydrogenation reaction conditions, in situ XANES spectra show reduction of $\mathrm{Ti}^{4+}$ to $\mathrm{Ti}^{3+}$ for all three catalysts, and $\mathrm{CoO}_{\mathrm{x}} / \mathrm{TiO}_{2} / \mathrm{Pt}$ and $\mathrm{CoO}_{x} \mathrm{Pt} / \mathrm{TiO}_{2}$ possess more reduced $\mathrm{Ti}^{3+}$ than that of the $\mathrm{TiO}_{2} / \mathrm{Pt}$ catalyst. The $\mathrm{k}^{3}$-weighted EXAFS spectra of the three catalysts and the reference $\mathrm{TiO}_{2}$, and their fitted curves are presented in Supplementary Fig. 15. The fitted results (Supplementary Table 2) are consistent with the XANES results.

Chemisorption. Figure 4a shows the $\mathrm{H}_{2}$ temperature programmed reduction $\left(\mathrm{H}_{2}-\mathrm{TPR}\right)$ profiles of the catalysts. From the $\mathrm{H}_{2}$-TPR profiles of the $\mathrm{CoO}_{x} \mathrm{Pt} / \mathrm{TiO}_{2}, \mathrm{CoO}_{x} / \mathrm{TiO}_{2} / \mathrm{Pt}$ and $\mathrm{CoO}_{x} /$ $\mathrm{TiO}_{2}$ catalysts (also see Supplementary Fig. 10), both a low temperature $\left(110-220^{\circ} \mathrm{C}, \mathrm{Co}_{3} \mathrm{O}_{4}\right.$ to $\left.\mathrm{CoO}\right)$ and a high temperature $\left(245-345^{\circ} \mathrm{C}, \mathrm{CoO}\right.$ to $\left.\mathrm{Co}^{0}\right)$ reduction peak can be observed. No peaks related to platinum oxides are observed, probably because the amounts of $\mathrm{H}_{2}$ used for the reduction of $\mathrm{PtO}_{\mathrm{x}}$ species in the catalysts are beyond the lower detection limits of the detector. In addition, the reduction peak at higher temperature $\left(\sim 450^{\circ} \mathrm{C}\right)$ could be assigned to the partial reduction of $\mathrm{TiO}_{2}$, indicating that $\mathrm{TiO}_{2}$ is more difficult to reduce ${ }^{42}$. Compared with the $\mathrm{CoO}_{x} / \mathrm{TiO}_{2}$ catalysts, the temperatures needed for $\mathrm{CoO}_{x}$ reduction are much lower for the $\mathrm{CoO}_{x} \mathrm{Pt} / \mathrm{TiO}_{2}$ and $\mathrm{CoO}_{x} / \mathrm{TiO}_{2} / \mathrm{Pt}$ catalysts due to the presence of $\mathrm{Pt}$, further revealing the effect of hydrogen spillover from $\mathrm{Pt}$ to $\mathrm{CoO}_{x}{ }^{31}$. Note that the reduction temperature needed for the $\mathrm{CoO}_{x} \mathrm{Pt} / \mathrm{TiO}_{2}$ catalyst is slightly lower than that of the $\mathrm{CoO}_{x} / \mathrm{TiO}_{2} / \mathrm{Pt}$ catalyst due to the closer $\mathrm{CoO}_{x}-\mathrm{Pt}$ intimacy
(Fig. 4a). Figure $4 \mathrm{~b}$ shows the $\mathrm{H}_{2}$ temperature programmed desorption $\left(\mathrm{H}_{2}-\mathrm{TPD}\right)$ profiles of the catalysts. The $\mathrm{TiO}_{2} / \mathrm{Pt}$ and $\mathrm{CoO}_{x} / \mathrm{TiO}_{2} / \mathrm{Pt}$ catalysts exhibit a much higher $\mathrm{H}_{2}$ adsorption ability than that of the $\mathrm{CoO}_{x} / \mathrm{TiO}_{2}$ and $\mathrm{CoO}_{x} \mathrm{Pt} / \mathrm{TiO}_{2}$ catalysts, indicating that $\mathrm{Pt}$ atoms are the adsorption and dissociation sites of $\mathrm{H}_{2}$, which is further verified by the following density functional theory (DFT) simulation.

\section{Discussion}

In this work, we discovered a hydrogen spillover effect for the CALD hydrogenation reactions. Hydrogen spillover is a reversible and dynamic equilibrium process. Modulation of the spillover conditions, such as temperature and gas partial pressure, hinders or facilitates the spillover process and can be used for controlling the oxide reduction ${ }^{7,43}$. Generally, the activation and dissociation of $\mathrm{H}_{2}$ molecules on $\mathrm{Pt}$ is quite easy and generally considered to be barrierless ${ }^{7,43-45}$, i.e., the energy needed to activate $\mathrm{H}_{2}$ molecules on $\mathrm{Pt}$ is much lower than that on $\mathrm{CoO}_{x}$ and $\mathrm{TiO}_{2}$ (Supplementary Fig. 16). For the $\mathrm{TiO}_{2} / \mathrm{Pt}$ catalyst under the reaction conditions, hydrogen spillover occurs (Fig. 5a). Active hydrogen species migrate from $\mathrm{Pt}$ onto $\mathrm{TiO}_{2}$ supports, leading to the partial reduction of $\mathrm{TiO}_{2}$ supports $\left(\mathrm{Ti}^{4+}\right.$ is reduced to $\left.\mathrm{Ti}^{3+}\right)$ with the formation of $\mathrm{O}_{\mathrm{v}}$ around the interface regions $\mathrm{s}^{7,46-50}$. When $\mathrm{CoO}_{x}$ is added, in situ XAFS results show that $\mathrm{CoO}_{x}$ can be reduced to lower valent states through hydrogen spillover under the reaction conditions. More hydrogen species are consumed by $\mathrm{CoO}_{x}$, thus the original equilibrium of hydrogen spillover is disturbed (Fig. 5a). The generation of active hydrogen species and their transfer process (from $\mathrm{Pt}$ to $\mathrm{CoO}_{x}$ directly, or via $\mathrm{TiO}_{2}$ supports) are promoted, until new equilibrium is reached. The consumption of hydrogen species can be seen as the pumps for the migration of atomic hydrogen from $\mathrm{Pt}$ toward $\mathrm{TiO}_{2}$. The enhanced hydrogen spillover facilitates the reduction of $\mathrm{TiO}_{2}$ supports, which is proved by in situ Ti K-edge XANES spectra (Fig. $3 \mathrm{c}$ and f), accompanying the increased formation of $\mathrm{O}_{\mathrm{v}}$ sites.

The adsorption energies of different adsorption configurations of a CALD molecule on the $\mathrm{O}_{\mathrm{v}}$ formed on $\mathrm{TiO}_{2}$ were calculated (Fig. 5b). The calculated adsorption energy of the $\mathrm{C}=\mathrm{O}$ bond adsorbed on the oxygen vacancies is $-2.38 \mathrm{eV}$, which is larger than that of the $\mathrm{C}=\mathrm{C}$ bond on the oxygen vacancies $(-1.68 \mathrm{eV})$, indicating that the adsorption configurations of the CALD molecule through the $\mathrm{C}=\mathrm{O}$ bond on the $\mathrm{O}_{\mathrm{v}}$ are more stable.

Based on the above discussions, the possible enhancement mechanism is proposed. For the $\mathrm{TiO}_{2} / \mathrm{Pt}$ catalyst, the number of $\mathrm{O}_{\mathrm{v}}$ at the Pt- $\mathrm{TiO}_{2}$ interface is limited under the reaction conditions, leading to its low selectivity (Fig. $5 \mathrm{c}$ ). When $\mathrm{CoO}_{x}$ promoters are added, the selectivity to CALC is improved. The promotion can be ascribed to the $\mathrm{CoO}_{x}$ promoter-induced 
a
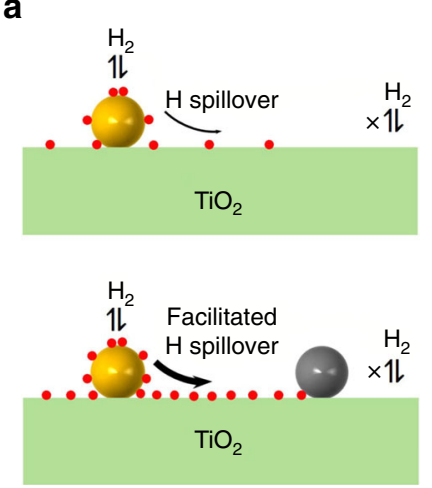

b

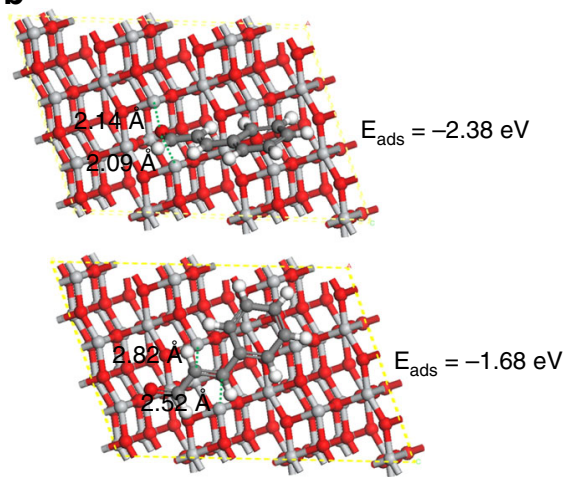

C
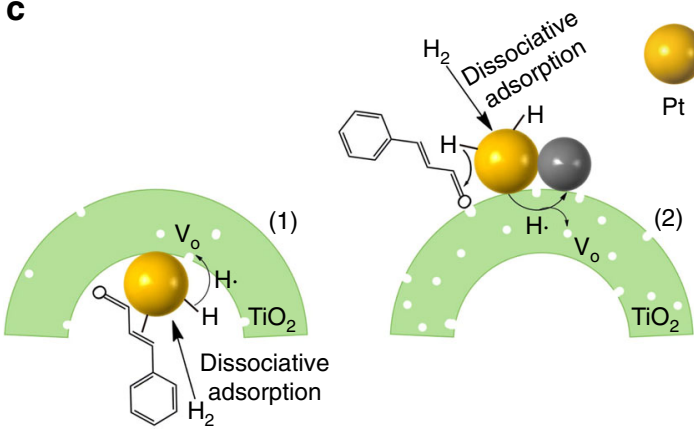

Vo: Oxygen vacancy

$\mathrm{CoO}_{x}$

(2)

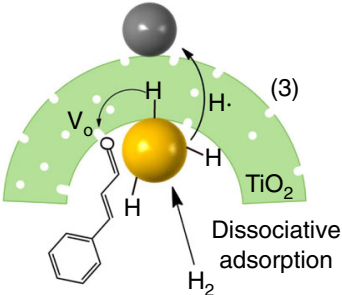

Fig. 5 DFT calculation and proposed reaction mechanisms. a The effect mechanism of $\mathrm{CoO}_{x}$ on the hydrogen spillover over $\mathrm{TiO}_{2}$-supported Pt catalysts. $\mathbf{b}$ The optimized structure for adsorption of CALD molecule using $\mathrm{C}=\mathrm{O}$ (top) or $\mathrm{C}=\mathrm{C}$ (bottom) double bond on the $\mathrm{O}_{\mathrm{v}}$ of $\mathrm{TiO}_{2}$. Atom coloring: $\mathrm{Ti}$, gray; $\mathrm{O}$, red; $\mathrm{H}$, white; $\mathrm{C}$, black. c The possible enhancement mechanism for selective CALD hydrogenation reaction. (1), (2) and (3) represent $\mathrm{TiO}_{2} / \mathrm{Pt}, \mathrm{CoO}_{x} \mathrm{Pt} / \mathrm{TiO}_{2}$ and $\mathrm{CoO}_{x} / \mathrm{TiO}_{2} / \mathrm{Pt}$ catalysts, respectively. For $\mathrm{TiO}_{2} / \mathrm{Pt}$, the number of $\mathrm{O}_{\mathrm{v}}$ is limited, leading to its low selectivity. For $\mathrm{CoO}_{x} \mathrm{Pt}_{/} / \mathrm{TiO}_{2}$ and $\mathrm{CoO}_{x} / \mathrm{TiO}_{2} / \mathrm{Pt}$, the addition of $\mathrm{CoO}_{x}$ promotes the formation of $\mathrm{O}_{v}$ sites through hydrogen spillover and thus improves the selectivity, regardless of whether $\mathrm{CoO}$ and $\mathrm{Pt}$ are separated by a $\mathrm{TiO}_{2}$ layer or not

increase of $\mathrm{O}_{\mathrm{v}}$ sites through hydrogen spillover effect. For $\mathrm{CoO}_{x} /$ $\mathrm{TiO}_{2} / \mathrm{Pt}$ catalysts, although $\mathrm{CoO}_{x}$ is separated from the Pt catalyst by a $\mathrm{TiO}_{2}$ layer, this long-range $\mathrm{CoO}_{x}$ promoter can still enhance the catalytic selectivity to CALC. XAFS results demonstrate that the electronic states of $\mathrm{CoO}_{x}$ of $\mathrm{CoO}_{x} \mathrm{Pt} / \mathrm{TiO}_{2}$ and $\mathrm{CoO}_{x} / \mathrm{TiO}_{2} / \mathrm{Pt}$ catalysts are almost the same during the reaction process, meaning that the active hydrogen species generated on $\mathrm{Pt}$ nanoparticles are still consumed by $\mathrm{CoO}_{x}$, though $\mathrm{CoO}_{x}$ is far from $\mathrm{Pt}$. The energy barrier for the transfer of an electron and a proton among the different $\mathrm{TiO}_{2}$ sites can be easily overcome under the reaction conditions ${ }^{7}$, and thus the distance of hydrogen spillover across $\mathrm{TiO}_{2}$ layer almost has no influence on the catalytic performance. The addition of $\mathrm{CoO}_{x}$ results in the increased generation of $\mathrm{O}_{\mathrm{v}}$ sites on the $\mathrm{Pt}-\mathrm{TiO}_{2}$ interface regions and the remarkably improved selectivity to CALC.

To further clarify the long-range promoter effect (i.e., the role of $\mathrm{CoO}_{x}$ played), we selectively deposit additional oxide layers on the surfaces of $\mathrm{CoO}_{x}$ or Pt by ALD. From the XAFS results, it can be concluded that $\mathrm{CoO}_{x}$ species in the catalysts can be reduced in two ways. Firstly, the $\mathrm{CoO}_{x}$ species can be reduced under $\mathrm{H}_{2}$ atmosphere; secondly, the $\mathrm{CoO}_{x}$ species can be further reduced to a lower valence state by the active $\mathrm{H}$ species spilled from $\mathrm{Pt}$ nanoparticles through $\mathrm{TiO}_{2}$ support. When Pt is selectively covered by $\mathrm{TiO}_{2}\left(\mathrm{CoO}_{x} / \mathrm{TiO}_{2} / \mathrm{Pt} / \mathrm{TiO}_{2}\right)$, the access of CALD molecules to $\mathrm{Pt}$ is nearly blocked due to the diffusion limitation (Supplementary Figs. 17 and 18, Supplementary Table 3), leading to the decreased catalytic performance (Entry 6, Table 1). On the contrary, when $\mathrm{CoO}_{x}$ is selectively covered by a dense $\mathrm{Al}_{2} \mathrm{O}_{3}$ layer $\left(\mathrm{Al}_{2} \mathrm{O}_{3} / \mathrm{CoO}_{x} / \mathrm{TiO}_{2} / \mathrm{Pt}\right)$, the first way is blocked (Supplementary Fig. 18), while the second way is still preserved and CALD molecules can still have access to Pt via open the ends of the $\mathrm{TiO}_{2}$ nanotubes (with a diameter of $\sim 70-90 \mathrm{~nm}$ ), leading to a nearly unchanged catalytic performance (Entry 7 , Table 1). These results further demonstrate that $\mathrm{H}$ spillover way is the main path to improve selectivity, and that $\mathrm{Pt}-\mathrm{O}_{\mathrm{v}}$ interface instead of $\mathrm{CoO}_{x}$ should be the active site for the CALD hydrogenation reaction.

In summary, we have successfully developed a general method based on template-assisted ALD to synthesize closely contacted $\mathrm{CoO}_{x} \mathrm{Pt} / \mathrm{TiO}_{2}$ and spatially separated $\mathrm{CoO}_{x} / \mathrm{TiO}_{2} / \mathrm{Pt}$ catalysts, achieving the precise tuning of $\mathrm{CoO}_{x}-\mathrm{Pt}$ intimacy by varying the deposition sequence and the wall thickness of the $\mathrm{TiO}_{2}$ nanotubes. We discover that hydrogen spillover effect generated by the addition of $\mathrm{CoO}_{x}$ can cause the increase in $\mathrm{O}_{\mathrm{v}}$, providing the adsorption sites for $\mathrm{CALD}$ via $\mathrm{C}=\mathrm{O}$ bond and correspondingly resulting in the enhancement of selectivity to CALC in the CALD hydrogenation reactions. This hydrogen spillover effect is not broken even when we selectively deposit additional oxide layers on the $\mathrm{CoO}_{x}$ promoter by ALD to cover its surface entirely. Our work has demonstrated an efficient strategy based on ALD for the design of various bicomponent catalysts with distinct promoter-metal intimacy and the assembly of metals and oxide supports, which is helpful to reveal the origin of bicomponent synergy, the enhancement mechanism and the real active sites.

\section{Methods}

Synthesis of CNCs and the ALD process. The detailed CNC synthesis process and the ALD process can be found in our previous reports ${ }^{24-26}$.

Synthesis of $\mathrm{TiO}_{2} / \mathrm{Pt}$ catalysts. CNCs were firstly decorated with Pt nanoparticles by Pt ALD ( 20 cycles) and then coated with a $\mathrm{TiO}_{2}$ layer $(300$ cycles $)$ by $\mathrm{TiO}_{2}$ ALD, producing $\mathrm{TiO}_{2} / \mathrm{Pt} / \mathrm{CNCs}$. After the ALD processes, $\mathrm{TiO}_{2} / \mathrm{Pt} / \mathrm{CNCs}$ were calcinated at $500^{\circ} \mathrm{C}$ for $2 \mathrm{~h}$ in air to remove the CNC templates, obtaining $\mathrm{TiO}_{2} / \mathrm{Pt}$ catalysts, in which Pt nanoparticles were confined in $\mathrm{TiO}_{2}$ nanotubes. 
Synthesis of $\mathrm{CoO}_{x} / \mathrm{TiO}_{2} / \mathrm{Pt}$ catalysts. The above-obtained $\mathrm{TiO}_{2} / \mathrm{Pt}$ catalysts were then deposited with cobalt oxides (denoted as $\mathrm{CoO}_{x}$ ) by $\mathrm{CoO}_{x}$ ALD (150 cycles), obtaining shell-isolated $\mathrm{CoO}_{x} / \mathrm{TiO}_{2} / \mathrm{Pt}$ catalysts.

Synthesis of $\mathrm{CoO}_{\mathbf{x}} \mathbf{P t} / \mathrm{TiO}_{\mathbf{2}}$ catalysts. CNCs were firstly coated with a $\mathrm{TiO}_{2}$ amorphous film by $\mathrm{TiO}_{2} \mathrm{ALD}$, and then Pt nanoparticles were deposited on the $\mathrm{TiO}_{2} / \mathrm{CNCs}$ by Pt ALD obtaining Pt/TiO $/ 2$ CNCs composites. Subsequently, CNCs were removed by calcination under an air atmosphere producing $\mathrm{Pt} / \mathrm{TiO}_{2}$ catalysts with porous anatase nanotubes. Lastly, $\mathrm{CoO}_{x}$ nanoparticles were deposited on the outer surface of $\mathrm{Pt} / \mathrm{TiO}_{2}$ through $\mathrm{CoO}_{x} \mathrm{ALD}$, producing $\mathrm{CoO}_{x} \mathrm{Pt} / \mathrm{TiO}_{2}$ catalysts with the closest $\mathrm{CoO}_{x}-\mathrm{Pt}$ intimacy.

Synthesis of $\mathrm{CoO}_{\mathbf{x}} / \mathrm{TiO} \mathrm{O}_{2} / \mathrm{Pt} / \mathrm{TiO}_{2}$ catalysts. CNCs were first coated with a $\mathrm{TiO}_{2}$ layer (150 cycles) by $\mathrm{TiO}_{2} \mathrm{ALD}$ and then decorated with Pt nanoparticles by $\mathrm{Pt}$ ALD and another $\mathrm{TiO}_{2}$ layer (300 cycles) producing $\mathrm{TiO}_{2} / \mathrm{Pt} / \mathrm{TiO}_{2} / \mathrm{CNCs}$. After the ALD processes, $\mathrm{TiO}_{2} / \mathrm{Pt} / \mathrm{TiO}_{2} / \mathrm{CNCs}$ were calcinated at $500^{\circ} \mathrm{C}$ for $2 \mathrm{~h}$ in air to remove the CNC templates, obtaining sandwich-like $\mathrm{TiO}_{2} / \mathrm{Pt} / \mathrm{TiO}_{2}$ catalysts, in which $\mathrm{Pt}$ nanoparticles are coated by the two-layer $\mathrm{TiO}_{2}$. Lastly, the obtained $\mathrm{TiO}_{2} /$ $\mathrm{Pt} / \mathrm{TiO}_{2}$ catalysts were decorated with $\mathrm{CoO}_{x}$ nanoparticles by $\mathrm{CoO}_{x}$ ALD producing $\mathrm{CoO}_{\mathrm{x}} / \mathrm{TiO}_{2} / \mathrm{Pt} / \mathrm{TiO}_{2}$.

Synthesis of $\mathrm{Al}_{2} \mathrm{O}_{3} / \mathrm{CoO}_{x} / \mathrm{TiO}_{2} / \mathrm{Pt}$ catalysts. CNCs were sequentially decorated with $\mathrm{Pt}$ nanoparticles by $\mathrm{CoO}_{x} \mathrm{ALD}$, coated with a $\mathrm{TiO}_{2}$ layer (300 cycles) by $\mathrm{TiO}_{2}$ ALD, decorated with Pt nanoparticles by Pt ALD and then coated with an $\mathrm{Al}_{2} \mathrm{O}_{3}$ layer (100 cycles) by $\mathrm{Al}_{2} \mathrm{O}_{3} \mathrm{ALD}$ producing $\mathrm{Al}_{2} \mathrm{O}_{3} / \mathrm{CoO}_{x} / \mathrm{TiO}_{2} / \mathrm{Pt} / \mathrm{CNCs}$, which were calcinated at $550{ }^{\circ} \mathrm{C}$ for $2 \mathrm{~h}$ in air to remove the CNC templates obtaining $\mathrm{Al}_{2} \mathrm{O}_{3} / \mathrm{CoO}_{x} / \mathrm{TiO}_{2} / \mathrm{Pt}$ catalysts, in which $\mathrm{CoO}_{x}$ nanoparticles were covered by the outer $\mathrm{Al}_{2} \mathrm{O}_{3}$ layer.

Catalyst characterizations. TEM and HRTEM images were taken with a JEOL$2100 \mathrm{~F}$ field-emission transmission electron microscope operated at $200 \mathrm{kV}$. HAADF-STEM images and EDS mapping profiles were collected on a JEOL ARM$200 \mathrm{~F}$ field-emission transmission electron microscope operated at $200 \mathrm{kV}$. The Xray diffraction $(\mathrm{XRD})$ patterns were recorded by using a Philips X'Pert Pro Super $\mathrm{X}$-ray diffractometer with $\mathrm{Cu} \mathrm{Ka}$ radiation $(\lambda=1.540 \AA)$ in the $2 \theta$ range from $10^{\circ}$ to $90^{\circ}$. The X-ray photoelectron spectra (XPS) were collected on an ESCALab-250 $\mathrm{X}$-ray photoelectron spectrometer with an $\mathrm{Al} \mathrm{Ka}$ source $(1486.6 \mathrm{eV})$. The XANES and EXAFS spectra of the $\mathrm{Pt}_{\mathrm{L}_{3}}$-edge and Co K-edge were measured on the BL14W1 beamline of the Shanghai Synchrotron Radiation Facility (SSRF), Shanghai Institute of Applied Physics (SINAP), China, operated at $3.5 \mathrm{GeV}$. A Si (111) double-crystal monochromator was used to reduce the harmonic component of the monochrome beam. Pt foil, $\mathrm{PtO}_{2}$, Co foil, $\mathrm{CoO}$ and $\mathrm{Co}_{3} \mathrm{O}_{4}$ were used as reference samples and measured in the transmission mode, and all the catalysts were also measured in the transmission mode. The diffuse reflectance infrared Fourier transform spectroscopy (DRIFTS, CO chemisorption) measurements were performed on a Bruker Vector 22 spectrometer. After the sample was loaded, it was firstly reduced by $10 \% \mathrm{H}_{2} / \mathrm{Ar}$ at $150^{\circ} \mathrm{C}$ for $1.5 \mathrm{~h}$. Then the sample was cooled to $30{ }^{\circ} \mathrm{C}$ under $10 \% \mathrm{H}_{2} / \mathrm{Ar}$ atmosphere, on which a background spectrum was collected. Subsequently, $\mathrm{CO}$ was introduced onto the sample until saturation, followed by $\mathrm{Ar}$ purge to remove the physically adsorbed gaseous CO. Finally, CO-DRIFTS spectra were collected with 250 scans. $\mathrm{H}_{2}$-TPR experiments were performed in a tubular quartz reactor (TP-5080, Tianjin Xianquan, China), into which $50 \mathrm{mg}$ sample was loaded. The reduction was conducted in a $10 \% \mathrm{H}_{2} / \mathrm{N}_{2}$ atmosphere at a heating rate of $10^{\circ} \mathrm{C} / \mathrm{min}$. $\mathrm{H}_{2}$-TPD experiments were performed in the same apparatus. A $50-\mathrm{mg}$ sample was firstly reduced in situ at $250^{\circ} \mathrm{C}$ for $1 \mathrm{~h}$ in a $10 \% \mathrm{H}_{2} /$ $\mathrm{N}_{2}$ flow and then cooled to $30^{\circ} \mathrm{C}$ in the same atmosphere. Subsequently, the sample was swept with nitrogen at a flow rate of $30 \mathrm{sccm}$ for $30 \mathrm{~min}$ to remove physisorbed or weakly bound species. TPD was performed by heating the sample from room temperature to $800^{\circ} \mathrm{C}$ at a ramp rate of $10^{\circ} \mathrm{C} / \mathrm{min}$ in nitrogen. $\mathrm{N}_{2}$ adsorption-desorption experiments were performed on a BELSORP-Mini system at $77 \mathrm{~K}$. The specific surface area was determined using the Brunauer-Emmett-Teller (BET) method, and the pore size distributions were calculated by the Barrett-Joyner-Halenda (BJH) method according to the desorption branches. The Pt and Co metal content of the samples was determined by inductively coupled plasma mass spectrometry (ICP-MS) analysis (Thermo ICAP 6300).

Catalytic activity measurements. CALD hydrogenation reactions were performed on the above catalysts in a 50-mL stainless-steel autoclave reactor. The reaction was carried out at $65^{\circ} \mathrm{C}$ and $2.0 \mathrm{MPa} \mathrm{H}_{2}$ with a certain amount of catalysts in $30 \mathrm{~mL}$ of ethanol, and $100 \mu \mathrm{L}$ of CALD. After the reaction, the reactor was cooled and then slowly depressurized. Finally, the reaction mixture was separated by centrifugation in order to remove the solid catalysts. The reaction products were analyzed and quantified by gas chromatographic mass spectrometry (GC-MS, Agilent, 7890A). The reaction conversion and selectivity were determined by the product analysis.

Computational method. Periodic DFT calculations within the generalized gradient approximation $(\mathrm{GGA})$ were conducted with the Vienna ab initio Simulation
Package (VASP 5.3.5) with considering the spin-polarization, in which a projectoraugmented potential (PAW) method is implemented. The

Perdew-Burke-Ernzerhof (PBE) functional at the GGA level was used, and the plane wave basis set was cut off at the energy of $400 \mathrm{eV}$. For our ALD-prepared cobalt-based catalysts, the obtained cobalt oxides consist of $\mathrm{Co}_{3} \mathrm{O}_{4}$ and $\mathrm{CoO}$ and the main species is $\mathrm{CoO}$. Therefore, $\mathrm{CoO}$ was selected for DFT calculations. The $\mathrm{CoO}$ surface was modeled with a six GGA extension atomic layer $3 \times 3 \mathrm{CoO}(111)$ slab. DFT $+\mathrm{U}$ corrections (an effective onsite Coulomb interaction parameter) were employed to mitigate the self-interaction errors of Co $3 \mathrm{~d}$ orbital with U-J of $7.1 \mathrm{eV}$. The main exposed crystal plane for ALD-prepared $\mathrm{TiO}_{2}$ is the thermodynamically most stable (101) surface, and thus (101) surface was chosen as a model for the anatase $\mathrm{TiO}_{2}$ interface. The $\mathrm{TiO}_{2}$ surface was modeled with a six atomic layer $3 \times 3$ slab. The slab and its image were separated by a vacuum region of $15 \AA$. The reactant molecular and the top two layers of these model systems were relaxed, whereas other atoms were fixed in their initial lattice sizes.

\section{Data availability}

All the relevant data are available from the authors upon request.

Received: 5 December 2018 Accepted: 14 August 2019

Published online: 13 September 2019

\section{References}

1. Tao, F. F. Synthesis, catalysis, surface chemistry and structure of bimetallic nanocatalysts. Chem. Soc. Rev. 41, 7977-7979 (2012).

2. Sankar, M. et al. Designing bimetallic catalysts for a green and sustainable future. Chem. Soc. Rev. 41, 8099-8139 (2012).

3. Behrens, M. et al. Performance improvement of nanocatalysts by promoterinduced defects in the support material: methanol synthesis over $\mathrm{Cu} / \mathrm{ZnO} \mathrm{Al}$ J. Am. Chem. Soc. 135, 6061-6068 (2013)

4. Briggs, N. M. et al. Identification of active sites on supported metal catalysts with carbon nanotube hydrogen highways. Nat. Commun. 9, 3827 (2018).

5. Phaahlamohlaka, T. N. et al. Effects of Co and Ru intimacy in Fischer-Tropsch catalysts using hollow carbon sphere supports: assessment of the hydrogen spillover processes. ACS Catal. 7, 1568-1578 (2017)

6. Zhang, $\mathrm{H}$. et al. Revealing the role of interfacial properties on catalytic behaviors by in situ surface-enhanced raman spectroscopy. J. Am. Chem. Soc. 139, 10339-10346 (2017)

7. Karim, W. et al. Catalyst support effects on hydrogen spillover. Nature 541, 68-71 (2017).

8. Samad, J. E., Blanchard, J., Sayag, C., Louis, C. \& Regalbuto, J. R. The controlled synthesis of metal-acid bifunctional catalysts: the effect of metal: acid ratio and metal-acid proximity in Pt silica-alumina catalysts for nheptane isomerization. J. Catal. 342, 203-212 (2016).

9. Cheng, K. et al. Direct and highly selective conversion of synthesis gas into lower olefins: design of a bifunctional catalyst combining methanol synthesis and carbon-carbon coupling. Angew. Chem. Int. Ed. Engl. 128, 4803-4806 (2016)

10. Gläser, R. Catalysis: the complexity of intimacy. Nature 528, 197-198 (2015)

11. Lu, J., Elam, J. W. \& Stair, P. C. Synthesis and stabilization of supported metal catalysts by atomic layer deposition. Acc. Chem. Res. 46, 1806-1815 (2013).

12. Lee, H.-B.-R. \& Bent, S. F. Formation of continuous Pt films on the graphite surface by atomic layer deposition with reactive $\mathrm{O}_{3}$. Chem. Mater. 27, 6802-6809 (2015)

13. O'Neill, B. J. et al. Catalyst design with atomic layer deposition. ACS Catal. 5 , 1804-1825 (2015)

14. Liu, X. et al. Oxide-nanotrap-anchored platinum nanoparticles with high activity and sintering resistance by area-selective atomic layer deposition. Angew. Chem. Int. Ed. Engl. 129, 1670-1674 (2017).

15. Meng, X. et al. Atomic layer deposition for nanomaterial synthesis and functionalization in energy technology. Mater. Horiz. 4, 133-154 (2017).

16. Gao, Z. \& Qin, Y. Design and properties of confined nanocatalysts by atomic layer deposition. Acc. Chem. Res. 50, 2309-2316 (2017).

17. Dendooven, J. et al. Independent tuning of size and coverage of supported Pt nanoparticles using atomic layer deposition. Nat. Commun. 8, 1074 (2017).

18. $\mathrm{Lu}$, J. et al. Coking- and sintering-resistant palladium catalysts achieved through atomic layer deposition. Science 335, 1205-1208 (2012).

19. Zhang, J. et al. Highly dispersed Pt nanoparticles supported on carbon nanotubes produced by atomic layer deposition for hydrogen generation from hydrolysis of ammonia borane. Catal. Sci. Technol. 7, 322-329 (2017).

20. Gould, T. D. et al. Controlling nanoscale properties of supported platinum catalysts through atomic layer deposition. ACS Catal. 5, 1344-1352 (2015).

21. Cheng, N. et al. Platinum single-atom and cluster catalysis of the hydrogen evolution reaction. Nat. Commun. 7, 13638 (2016). 
22. Van Bui, H., Grillo, F., Helmer, R., Goulas, A. \& van Ommen, J. R. Controlled growth of palladium nanoparticles on graphene nanoplatelets via scalable atmospheric pressure atomic layer deposition. J. Phys. Chem. C 120, 8832-8840 (2016).

23. Wang, X. et al. Atomic layer deposited Pt-Co bimetallic catalysts for selective hydrogenation ofa, $\alpha, \beta$-unsaturated aldehydes to unsaturated alcohols. J. Catal. 366, 61-69 (2018).

24. Gao, Z. et al. Multiply confined nickel nanocatalysts produced by atomic layer deposition for hydrogenation reactions. Angew. Chem. Int. Ed. Engl. 54, 9006-9010 (2015).

25. Ge, H. et al. A tandem catalyst with multiple metal oxide interfaces produced by atomic layer deposition. Angew. Chem. Int. Ed. Engl. 128, 7197-7201 (2016).

26. Zhang, J. et al. Porous $\mathrm{TiO}_{2}$ nanotubes with spatially separated platinum and CoOx cocatalysts produced by atomic layer deposition for photocatalytic hydrogen production. Angew. Chem. Int. Ed. Engl. 56, 816-820 (2017).

27. Ramachandran, R. K. et al. Atomic layer deposition route to tailor nanoalloys of noble and non-noble metals. ACS Nano 10, 8770-8777 (2016).

28. Mao, S. et al. High-performance bi-functional electrocatalysts of $3 \mathrm{D}$ crumpled graphene-cobalt oxide nanohybrids for oxygen reduction and evolution reactions. Energy Environ. Sci. 7, 609-616 (2014).

29. Plomp, A. J. et al. Particle size effects for carbon nanofiber supported platinum and ruthenium catalysts for the selective hydrogenation of cinnamaldehyde. Appl. Catal. A Gen. 351, 9-15 (2008).

30. Yu, W., Porosoff, M. \& Chen, J. G. Review of Pt-based bimetallic catalysis: from model surfaces to supported catalysts. Chem. Rev. 112, 5780-5817 (2012).

31. Zheng, R. et al. Controlling hydrogenation of $\mathrm{C}=\mathrm{O}$ and $\mathrm{C}=\mathrm{C}$ bonds in cinnamaldehyde using silica supported $\mathrm{Co}-\mathrm{Pt}$ and $\mathrm{Cu}-\mathrm{Pt}$ bimetallic catalysts. Appl. Catal. A Gen. 419-420, 126-132 (2012).

32. Nongwe, I. et al. Pt supported nitrogen doped hollow carbon spheres for the catalysed reduction of cinnamaldehyde. Appl. Catal. A Gen. 517, 30-38 (2016).

33. Wu, B. et al. Selective hydrogenation of $\alpha, \beta$-unsaturated aldehydes catalyzed by amine-capped platinum-cobalt nanocrystals. Angew. Chem. Int. Ed. Engl. 51, 3440-3443 (2012).

34. Ji, X. et al. Selective hydrogenation of cinnamaldehyde to cinnamal alcohol over platinum/graphene catalysts. ChemCatChem 6, 3246-3253 (2014).

35. Wang, $\mathrm{H}$. et al. A strongly coupled ultrasmall $\mathrm{Pt}_{3} \mathrm{Co}$ nanoparticle-ultrathin $\mathrm{Co}$ $(\mathrm{OH})_{2}$ nanosheet architecture enhances selective hydrogenation of $\alpha, \beta$ unsaturated aldehydes. ACS Catal. 9, 154-159 (2019).

36. $\mathrm{Li}, \mathrm{C}$. et al. The remarkable promotion of in situ formed Pt-cobalt oxide interfacial sites on the carbonyl reduction to allylic alcohols. Mol. Catal. 455, 78-87 (2018)

37. Guo, Z. et al. Carbon nanotube-supported Pt-based bimetallic catalysts prepared by a microwave-assisted polyol reduction method and their catalytic applications in the selective hydrogenation. J. Catal. 276, 314-326 (2010).

38. Tsang, S. C. et al. Engineering preformed cobalt-doped platinum nanocatalysts for ultraselective hydrogenation. ACS Nano 2, 2547-2553 (2008).

39. Kennedy, G., Melaet, G., Han, H.-L., Ralston, W. T. \& Somorjai, G. A. In situ spectroscopic investigation into the active sites for crotonaldehyde hydrogenation at the Pt nanoparticle- $\mathrm{Co}_{3} \mathrm{O}_{4}$ interface. ACS Catal. 6, 7140-7147 (2016).

40. Zhao, M. et al. Metal-organic frameworks as selectivity regulators for hydrogenation reactions. Nature 539, 76-80 (2016).

41. Zheng, R., Zhu, Y. \& Chen, J. G., Promoting low-temperature hydrogenation of $\mathrm{C}=\mathrm{O}$ bonds of acetone and acetaldehyde by using $\mathrm{Co}-\mathrm{Pt}$ bimetallic catalysts. Chem CatChem 3, 578-581 (2011).

42. Zhu, Y., Liu, D. \& Meng, M. $\mathrm{H}_{2}$ spillover enhanced hydrogenation capability of $\mathrm{TiO}_{2}$ used for photocatalytic splitting of water: a traditional phenomenon for new applications. Chem. Commun. 50, 6049-6051 (2014).

43. Spreafico, C. et al. Hydrogen adsorption on nanosized platinum and dynamics of spillover onto alumina and titania. J. Phys. Chem. C 121, 17862-17872 (2017).

44. Kyriakou, G. et al. Isolated metal atom geometries as a strategy for selective heterogeneous hydrogenations. Science 335, 1209-1212 (2012).
45. Zhan, G. \& Zeng, H. Hydrogen spillover through Matryoshka-type (ZIFs@)

46. Prins, R. Hydrogen spillover. Facts and fiction. Chem. Rev. 112, 2714-2738 (2012).

47. Im, J. et al. Maximizing the catalytic function of hydrogen spillover in platinum-encapsulated aluminosilicates with controlled nanostructures. Nat. Commun. 5, 3370 (2014).

48. Ruiz Puigdollers, A., Schlexer, P., Tosoni, S. \& Pacchioni, G. Increasing oxide reducibility: the role of metal/oxide interfaces in the formation of oxygen vacancies. ACS Catal. 7, 6493-6513 (2017).

49. Conner, W. C. Jr \& Falconer, J. L. Spillover in heterogeneous catalysis. Chem. Rev. 95, 759-788 (1995).

50. An, K. et al. Enhanced CO oxidation rates at the interface of mesoporous oxides and Pt nanoparticles. J. Am. Chem. Soc. 135, 16689-16696 (2013).

\section{Acknowledgements}

We acknowledge the financial support from the National Natural Science Foundation of China (21773282, U1832208 and 21673269), National Science Fund for Distinguished Young Scholars (21825204), the National Key R\&D Program of China (2017YFA0700101), Natural Science Foundation of Shanxi Province (201801D211011) Excellent Youth Scholars of State Key Laboratory of Coal Conversion (2016BWZ004), Youth Innovation Promotion Association of the Chinese Academy of Sciences (2018208) and National Postdoctoral Program for Innovative Talents (BX20180323). We are grateful to Shanghai Institute of Applied Physics for the X-ray absorption spectroscopy measurement.

\section{Author contributions}

J.Z. synthesized the catalysts and performed the activity tests. S.W. performed the theoretical calculation. G.W. helped to perform the XAFS measurement. X.G., B.Z., S.X. and S.Z. assisted in the synthesis and characterizations of the catalysts. Z.G. and Y.Q. conceived the idea and supervised the work. J.Z., Z.G. and Y.Q. wrote the manuscript. All authors contributed to the manuscript.

\section{Additional information}

Supplementary Information accompanies this paper at https://doi.org/10.1038/s41467019-11970-8.

Competing interests: The authors declare no competing interests.

Reprints and permission information is available online at http://npg.nature.com/ reprintsandpermissions/

Peer review information Nature Communications thanks Neil Coville and other, anonymous, reviewer(s) for their contribution to the peer review of this work.

Publisher's note Springer Nature remains neutral with regard to jurisdictional claims in published maps and institutional affiliations.

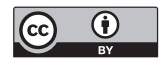

Open Access This article is licensed under a Creative Commons Attribution 4.0 International License, which permits use, sharing, adaptation, distribution and reproduction in any medium or format, as long as you give appropriate credit to the original author(s) and the source, provide a link to the Creative Commons license, and indicate if changes were made. The images or other third party material in this article are included in the article's Creative Commons license, unless indicated otherwise in a credit line to the material. If material is not included in the article's Creative Commons license and your intended use is not permitted by statutory regulation or exceeds the permitted use, you will need to obtain permission directly from the copyright holder. To view a copy of this license, visit http://creativecommons.org/ licenses/by/4.0/.

(C) The Author(s) 2019 